\title{
Las raíces del terrorismo moderno y su conexión con el mundo de las ideas. La relación entre nihilismo cultural y terrorismo político
}

Luis A. Aparicio Ordás González García

\section{Introducción}

Las ideas que inspiran el nacimiento del terrorismo moderno no son originales, sí lo son su justificación ideológica y su metodología las cuales han ido evolucionando a lo largo de la historia moderna. Determinados movimientos y corrientes ideológicas las recogen, las conceptualizan y las desarrollan en sus idearios políticos, las absorben, para señalar mediante una estrategia política definida llevar a cabo un ideal transformador radical y adelantar un determinado horizonte utópico. A lo largo de la historia, diversos autores, pensadores y teóricos serán los responsables de la transformación de una idea en un acto, de señalar que un fundamento teórico es un acto transformador de la sociedad, de afirmar un acontecimiento como absoluto.

Así mismo, resulta necesario analizar la relación entre un determinado nihilismo práctico, que, en la actualidad, se sitúa en la mentalidad y en el comportamiento general de los occidentales, para llegar a una serie de conclusiones sobre si existe una relación entre un fenómeno cultural como es el nihilismo, y un fenómeno político como es el terrorismo. 


\section{Las raíces de la violencia terrorista}

Los orígenes de la violencia con las características de lo que hoy entendemos por terrorismo hay que situarlos en plena Revolución Francesa, entre los años 1793 y 1794, cuando apareció una manifestación de violencia organizada. Las manifestaciones de este reflejo las vamos a ver repetidas a lo largo de la historia moderna y hasta el día de hoy por personas o grupos que van a utilizar un tipo de violencia política basada en el terror.

Walter Laqueur señala que "para entender el terrorismo, es preciso investigar en sus raíces antes de pasar a sus manifestaciones externas" (2003, p. 13). Si hacemos un recorrido por su geografía y analizamos la etiología del terrorismo podemos, en cierta medida, llegar a comprender sus raíces, pero esta comprensión no nos llevará muy lejos, formular una teoría general del terrorismo "una explicación global de sus raíces, es inútil e insensata” (Laqueur, 2003, p. 29).

Tanto para Walter Laqueur, como para David C. Rapoport - 25 años después-, el terrorismo se manifiesta siempre en oleadas, caracterizadas por un ciclo de actividad en un periodo determinado cuyo rasgo característico es su carácter internacional. Oleadas que aparecen y desaparecen en el tiempo, actividades similares que acontecen en varios países a un mismo tiempo, que tienen una dimensión espacial similar y una naturaleza idéntica, la existencia de paralelismos entre las pasadas amenazas terrorista y las presentes amenazas, hace que nos encontremos con paralelismos y similitudes que nos sorprenden y con las cuales podemos señalar la eclosión y la expansión de las oleadas o los ciclos de actividad terrorista a lo largo de la historia moderna, así como su contracción y agotamiento.

El terrorismo va a aparecer y desaparecer de la historia porque está vinculado a movimientos sociales transformadores y a acontecimientos políticos importantes. Para Walter Laqueur, al igual que para Robert Moss, la actividad terrorista se va a producir allí donde exista un cierto vacío de legitimidad, el atentado terrorista será un fenómeno esporádico si la legitimidad del sistema no se pone en cuestión. 
El terrorismo, como una forma específica de violencia política, pretende una transformación social radical y va a representar una trayectoria histórica de más de siglo y medio. Para Lamarca, el terrorismo puede ser definido sencillamente como "la violencia organizada con finalidad política” (1985, p. 95). ${ }^{1}$ En su estudio sobre las tipologías de terrorismo, Witker establece que el terrorismo ha sido desde siempre "un componente de la violencia política y se le debe aprehender como un instrumento de agresión, destinado a aniquilar o atemorizar al rival mediante el terror e intimidación de personas inocentes y no combatientes" (Witker, 2005, p. 28).

El estudio sistemático de este fenómeno de violencia y de terror presenta un origen muy reciente. El interés académico se inició en los años setenta del siglo XX, debido al enorme aumento de las acciones terroristas de la década anterior. Los objetivos de la investigación moderna van cambiando, pero el fenómeno terrorista sigue siendo un elemento problemático de investigación. Como destaca MacCormick, el terrorismo no solo es un instrumento de la política, sino también un instrumento del debate político. Hoy en día, siguen existiendo diferencias de definición entre terrorismo y otras formas de violencia política, sobre si se debe distinguir entre la naturaleza del acto y la naturaleza del actor, si el acto terrorista es un acto criminal o político, si la distinción debe ser cualitativa o cuantitativa con respecto a la distinción entre terrorismo y otras formas de violencia política, o si implica violencia o amenaza de violencia. Por su parte, Thornton define el terrorismo no por el estatus del autor, sino por la naturaleza del acto. Para MacCormick (2003, pp. 473-507), el acto terrorista se diseña para influir en un objetivo político atacando a otro, una actividad que en nombre de un determinado objetivo político es dirigida a un resultado determinado.

1 Para Lamarca, "La violencia así, es ejercida de un modo sistemático y planificado cuyo eje central es la existencia de una finalidad política, el grupo terrorista por tanto es portador de un determinado programa político, así, quedarían excluidas las expresiones de violencia que no tengan un objetivo político" (Lamarca, 1985). 


\section{El nacimiento del terrorismo moderno y su conexión con el mundo de las ideas}

En los procesos históricos del mundo político moderno se han ido desarrollando una serie de teorías y justificaciones que pasan por una aplicación táctica y estratégica del terrorismo. En 1849, el alemán Peter Karl Heinzen (1809-1880) publicó un ensayo titulado El asesinato (Der Mord) ${ }^{2}$ en el que sostienía la idea de la acción para conseguir objetivos políticos y a quien varios autores consideran el primer teórico del terrorismo (Buisson, 1999). Por otra parte, Karl Heinzen revisó las nociones clásicas del tiranicidio con la finalidad — según Burlegh- de legitimar el terrorismo (Burleigh, 2008, pp. 102-105).

En El asesinato se afirma que "el asesinato es el agente principal del progreso histórico". El racionamiento es sencillo: el Estado constantemente da carta de práctica política al asesinato, de modo que los revolucionarios están moralmente autorizados a recurrir a la misma táctica. Para Heinzen, todos los medios son válidos para apresurar el advenimiento de la democracia; en una versión posterior del mismo ensayo bajo el título Asesinato y libertad, Heinzen estableció a partir de las teorías sobre el tiranicidio una justificación del empleo del terrorismo. Para Burleing, en los escritos de Heinzen, "la antigua doctrina del tiranicidio se amplió hasta ser una doctrina del terrorismo moderno e indiscriminado". Heinzen establece una premisa: el revolucionario está plenamente, moralmente autorizado a utilizar la violencia, a recurrir a la misma táctica que emplea el poder político que representa un sistema de violencia.

Miller profundiza en los escritos de Heinzen, y resume su importancia: "la edad moderna de las teorías terroristas fue realizada por Heinzen". Heinzen concibe el terrorismo como un fenómeno transnacional, proporcionando una justificación material para las tácticas terroristas, el terrorismo como herramienta para impulsar al ser humano dentro de la sociedad y como una herramienta progresiva de la violencia. Para Patricia Kreibohm, "Heinzen formularía las bases de

2 El ensayo de Karl Heinzen se publicó en el periódico revolucionario Die Evolution. 
una de las primeras doctrinas específicas para el terrorismo subversivo; una doctrina en la cual el asesinato político aparecía como el único crimen plenamente justificado" (Kreibohm, 2005).

Para Walter Laqueur, Heinzen fue "el primero en proporcionar una doctrina sobre el terrorismo moderno" (Laqueur, 2003, p. 26). Sin embargo, tanto para Miller como para Laqueur, no se puede establecer una conexión entre Heinzen y los posteriores teóricos del terrorismo, más bien, su teoría se sitúa en un escalón intermedio entre las teorías tradicionales del tiranicidio y las teorías modernas sobre el terrorismo. Heinzen afirmó, que el asesinato debe transformarse en una ciencia, los revolucionarios tienen la obligación de convertir su debilidad en fortaleza política mediante una estrategia compensatoria de violencia de alto nivel (MacCormick, 2003).

Podemos continuar una trayectoria, que durante 50 años nos llevará al encuentro con diversos autores que van a desarrollar la doctrina moderna del terrorismo; así, podemos destacar a los siguientes autores:

- Piotr Zaichnevski (1842-1896) y su manifiesto Joven Rusia (Heller, 1985, p. 17).

- Paul Brousse (1844-1912) quien popularizó en un artículo publicado en agosto de 1877 titulado Propagande par le fait (Propaganda por el hecho), dicho término y donde analiza los movimientos revolucionarios como ejemplo de lo que debe ser la acción revolucionaria basada en dicho principio.

- Mijail Bakunin (1814-1876), para quien el terrorismo es una expresión individual, un acto de "destrucción redentora".

- Sergei Nechaiev (1847-1882), y su "Catecismo del Revolucionario" que fomentó la violencia y la destrucción sistemática de la sociedad burguesa. Edwar Hallet lo denominó “el primer terrorista”, puesto que creía en la destrucción del orden existente por medio de la revolución como dogma válido y suficiente por sí mismo (Avilés y Herrería, 2008, p. 196).

- Sergei Kravchinski (1852-1895), socialista revolucionario ruso que adquirió notoriedad al asesinar al jefe de la policía secreta rusa en San Petersburgo en 1878. Para Kravchinski, los actos individuales de terrorismo político convencerían al Emperador Alejandro II de introducir reformas democráticas en Rusia. 
- Nikolái Gavrílovich Chernyshevski (1828-1889) revolucionario y filósofo socialista ruso, líder del movimiento revolucionario conocido como Naródnik y de gran influencia en líderes como Vladímir Lenin.

- Lev Tikhomirov (1852-1923), profundamente influenciado por las ideas de Sergei Nechaiev, y quien creía posible que un pequeño grupo de revolucionarios mediante la utilización del terrorismo podrían hacerse directamente con el poder.

- Elisée Reclus (1830-1905), pensador anarquista francés.

- Gerasim Romanenko (1858-1927), para quién el terrorismo no solo era efectivo, sino también humanitario, ya que produce un número de víctimas infinitamente menor que la lucha de masas.

- Johann Most (1846-1906). Si Heinzen era un teórico Most era un hombre de acción. Most publicó una serie de artículos que posteriormente reunió en un libro titulado La ciencia de la guerra revolucionaria, todo un manual para el terrorista de la época, ${ }^{3}$ con detalles sobre armas, fabricación de explosivos, venenos o tinta invisible. Para Most la dinamita "remodelará las desigualdades y asimetrías con la que los insurgentes anarquistas habían de enfrentarse a las fuerzas regulares" (Burleigh, 2008, pp. 102-105). Most enfatizó la importancia de los explosivos como instrumento para llevar a cabo la revolución. Cuando el anarquista alemán August Reindorf fue decapitado por intentar asesinar al Káiser Guillermo I en 1885, Most publicó un artículo homenajeándole.

Carlo Piscane (1818-1857), considerado uno de los primeros defensores de esa "metáfora para la violencia de perfil alto": "la propaganda por el hecho". Para Piscane, "la propaganda es el resultado

3 Manual para la instrucción en el uso y la Preparación de nitroglicerina y dinamita, armas de fuego de algodón, fulminante de mercurio, bombas, fusibles, venenos, etc. Impreso y publicado por la Internationale Zeitungs Verein. Ver manual en www. chicagohistory. org/ hadc/transcript/Exhibits/ X000050/ X0150.htm - 3k - A finales del siglo XIX y principios del siglo XX los diversos grupos terroristas experimentarán con distintas tecnologías: explosivos mejorados, granadas de nitroglicerina, mecanismos detonadores, espoletas, máquinas incendiarias y mejores medios de emplearlos. 
de los hechos, y no los hechos resultado de las ideas, y las personas no son libres cuando están educadas, sino educadas cuando sean libres" (Hoffman, 1999, p. 21), concepto que fue popularizado por los anarquistas Carlo Cafiero (1846-1892) y Errico Malatesta (1853-1932). Para George Woodcock, en su obra El anarquismo, el concepto de "propaganda con los hechos" se remonta a Carlo Piscane, para quien las ideas eran resultados de los hechos. Para Laqueur, pensamientos similares se han expresado anteriormente, aunque no fue sino hasta 1876 cuando fue proclamada por los anarquistas Malatesta y Cafiero.

A finales del siglo XIX nació un nuevo modo de protesta política que tuvo en la figura de Francisco Ferrer i Guardia (1859-1909) el cerebro teórico de un nuevo enfoque en la articulación de la violencia para alcanzar un fin político (González, 1998, p. 143). Ferrer i Guardia comenzó a adquirir protagonismo a finales del siglo XIX, concretamente en octubre de 1892, a raíz del Congreso Universal de Librepensadores celebrado en Madrid. Su propuesta mostró rasgos novedosos con respecto al movimiento anarquista revolucionario, con la creación de una vanguardia de revolucionarios profesionales, el uso de nuevas tácticas (huelgas revolucionarias) y nuevas técnicas (magnicidios con dinamita), y lo más novedoso: concertar una alianza insurreccional con el resto de organizaciones proletarias. Fue editor del periódico $L a$ Huelga General y seguidor de las tácticas del sindicalismo revolucionario francés; propuso una visión científica de la revolución mediante la transformación del orden económico, la apropiación por parte de los trabajadores de los medios de producción y la destrucción de toda autoridad mediante la ejecución de un plan estricto de lucha armada.

El cénit de la conquista del poder se llevó a cabo por medio de "una huelga general redentora”. En 1901, Ferrer i Guardia creó la Escuela Moderna, en un intento de aplicar experiencias pedagógicas novedosas que incluían resolver el problema de la capacitación del proletariado urbano, con el fin de "preparar cerebros aptos para una revolución social”. Para Ferrer i Guardia, la articulación del impulso revolucionario pasaba por la preparación intelectual y la organización de las masas obreras, para llegado el momento, llevar a cabo una insurrección por 
medio de una huelga general revolucionaria. El 13 de octubre de 1909 Ferrer i Guardia fue ejecutado, señalado por el Gobierno de la época como autor y responsable de la llamada Semana trágica de Barcelona.

En 1929, en Estados Unidos, Alexander Berkman (1870-1936) publicó su obra El ABC del comunismo libertario, cuyo objetivo era transmitir los propósitos y los principios anarcocomunistas con el objetivo de dar un nuevo enfoque al movimiento anarquista internacional. Esta obra es "una articulación matizada de los principios anarquistas". En Berkman resulta interesante la reconsideración de la utilidad de la violencia revolucionaria en la transformación de la sociedad; según este autor, el camino más eficaz para conseguir los objetivos propuestos por el anarquismo pasa por crear "ejemplos prácticos de libertad e igualdad en los proyectos individuales y colectivos de la vida cotidiana". Recurrir a la violencia es calificado por Berkman, como "un método de ignorancia, un arma de los débiles". ${ }^{4}$ Así mismo, la revolución implicará un importante trabajo cultural, fundando en 1910, una Escuela Moderna, la "Francisco Ferrer Association" inspirada en los principios pedagógicos de Ferrer i Guardia en Barcelona.

\section{Del racionalismo socialista, al expresionismo anarquista. Táctica y procedimiento de los grupos terroristas}

A finales del siglo XIX y principios del siglo XX se desarrollaron dos corrientes, dos filosofías que definieron y hoy en día continúan definiendo el comportamiento de los grupos terroristas: una corriente

4 "Imagina una organización secreta que ha diseminado a sus miembros en pequeños grupos a través de todo el territorio del Imperio, pero que está, no obstante, unida firmemente: inspirada por un ideal común, una organización que actúa en todos los lados de acuerdo a un plan común. Estos grupos pequeños, desconocidos por todos en cuanto tales, no tienen poder reconocido oficialmente, pero son fuertes en sus ideales, los que expresan la verdadera esencia de los instintos del pueblo, sus deseos y demandas. Finalmente son fuertes en su solidaridad, lo que enlaza a todos estos grupos secretos en un todo orgánico" Carta de Bakunin a Nechaev. (2009) Disponible en: http://bibliotecanacionandaluzasevilla.files. wordpress.com 
racionalista desde una perspectiva del socialismo revolucionario, utilitarista y una corriente expresionista vinculada al anarquismo.

Para la corriente racionalista, utilitaria, la violencia fue un medio para alcanzar un fin; la actividad terrorista fue un medio, un instrumento de movilización política, el cual mediante una campaña de violencia tuvo como objetivo — como destacaba Nikolai Bukh- "levantar a las masas, despertarlas de su sueño de décadas y mostrar que existe una fuerza que lucha contra sus enemigos y a la vez protege su interés”. Esta filosofía de la violencia adoptó a finales del siglo XIX una forma crecientemente ideológica al verse atraída por la doctrina del socialismo revolucionario, que promovió un uso racional de la violencia y que consideró que las acciones terroristas son un instrumento político subordinado, pero significativo dentro de un programa más amplio de contenido revolucionario.

De esa manera, el terrorismo es una empresa colectiva con un alto nivel de organización y de planificación, clave para su éxito. Paradójicamente, Bakunin consideraba que cualquier fuerza que quiera derrocar al gobierno debe ser capaz de construir un aparato de partido cerrado, unido y disciplinado, esta idea que en su época no se llevó a la práctica se asemeja a las organizaciones terroristas de la actualidad.

Coexistiendo con esta corriente utilitaria de consecución mediante el terrorismo de un fin externo, se encontró la idea según la cual el terrorismo es una forma de expresión individual, un acto de redención; en palabras de Bakunin, "un acto de destrucción redentiva”. Recurrir al terrorismo es una elección existencial, la voluntad de matar y de morir en defensa de un ideal político es un acto personal de fe. Como se preguntó ante una mortal bomba anarquista en la Cámara de Diputados francesa, el intelectual anarquista Laurent Tailhade (1854-1919) “¿Qué importan las víctimas si el gesto es hermoso?”, el objetivo es llevar a cabo actos de terror. Esta corriente expresionista se vio atraída por las doctrinas anarquistas.

Para el ideal anarquista, someter a los individuos a la disciplina de organizaciones jerárquicas es contrario a los principios libertarios; acabar con el régimen solo podrá lograrse mediante combustión espontánea, no construyendo una contraorganización. Por lo tanto, el terrorismo es una decisión individual, es decir, el terrorismo individual 
modelará el futuro por medio de sus ejemplos lo que inspirará a otros y generará una dinámica que se autoalimentaría hasta que la sociedad se vuelva ingobernable y el propio Estado sea barrido.

Estas dos escuelas de pensamiento dieron lugar a dos modelos distintos de organización terrorista: por un lado, aquella que empleó el terrorismo para conseguir un fin externo, subordinando sus acciones a sus objetivos políticos y, por otro lado, aquella organización, cuyos objetivos son llevar a cabo actos de terror subordinando sus objetivos políticos a su necesidad de actuar, siendo en este caso la violencia un instrumento no de cambio político, sino un instrumento de expresión.

Cuando la clase obrera no es aún lo suficientemente avanzada en su organización como para llevar a cabo una campaña decisiva contra el poder colectivo; es decir, el poder político de las clases dominantes, debe en todo caso entrenarse para ello mediante una agitación continua y una actitud hostil a la política de las clases dominantes. De lo contrario, seguirá siendo un juguete en sus manos. (Marx, 1968)

\section{Los fenómenos inspiradores de las conductas terroristas: la relación entre nihilismo cultural y terrorismo político}

A finales del siglo XX, diversos autores e intelectuales han puesto en valor un determinado nihilismo práctico, poco elaborado doctrinalmente, con una onda penetración en la mentalidad y en el comportamiento general de los occidentales. Para estos pensadores, la mentalidad occidental se ha ido desprendiendo de cualquier militancia política o social, abandonando, así mismo, cualquier creencia religiosa, derivando en un comportamiento general hacia una mezcla de materialismo práctico y consumista, relativismo moral y naturalismo filosófico. Estas conclusiones, cuyo nacimiento y elaboración van a partir tanto de medios intelectuales como de entornos culturales o teológicos, encontraron un inesperado refuerzo en intelectuales como André Glucksmann, Jaques Brazun, Bernard Henry Lévy o Alain Finkielkraut. 
El nihilismo, como doctrina filosófica materialista, niega la existencia de cualquier creencia o realidad substancial. La realidad misma se remite a la propia nada. Ese todo discutible, en lo que ningún aspecto de la apariencia que conocemos como realidad sería objetivo.

Glucksmann (2005) en su obra El discurso del odio afirma: "es nihilista la voluntad de existir sin reglas o actuar sin prohibiciones", siguiendo a este pensador, el nihilismo es "una silueta insólita" que se encuentra "presente en todas las ideologías destructoras" (Franco, 2003, p. 100).

La tentación nihilista, como actitud, la podemos encontrar en las sociedades occidentales y en sus gobernantes, "como una respuesta extrema y catastrófica a un desarraigo creciente" (Glucksmann, 2005), donde los antiguos referentes religiosos se han desvanecido y las tradiciones milenarias van desapareciendo.

A parte de su sincronía en el tiempo, un fenómeno cultural como el nihilismo y un fenómeno político como el terrorismo ¿tienen entre sí alguna relación? A juzgar por la tipología humana, el terrorista es un ser activo fanático, obediente; y el nihilista se presenta como un ser apático, amónico e imprevisible. Fue a partir de que el terrorismo dio un salto cuantitativo con la aparición de los atentados más indiscriminados de la historia, es decir, con el nacimiento del terrorismo yihadista, cuya naturaleza no persigue un fin político, fin inherente al fenómeno terrorista clásico que considera el terrorismo como un fenómeno político, cuando ese terrorismo desprovisto de justificación y de reivindicación política aparece y trae consigo un deseo de aniquilar, pero sin posibilidad de sustitución.

Hemos encontrado en la organización terrorista rusa Narodnaya Volya (Voluntad del Pueblo), ${ }^{5}$ organización nutrida por igual de nihi-

5 El nacimiento de la violencia política se encuentra en la aparición del grupo ruso Narodnaya Volya (Voluntad del Pueblo) en 1878 y que asesinó al zar Alejandro II en 1881. Fue el primer grupo terrorista en utilizar la dinamita a gran escala. "Uno de sus miembros Serge Kibulchich, era un competente científico que introdujo importantes innovaciones como la de la mezcla de la nitroglicerina con otras sustancias, valiéndose del fulminante de mercurio como detonador". 
lismo y anarquismo, una configuración ideológica del actual terrorismo moderno. Los militantes de esta organización estaban dispuestos a sacrificar sus vidas en aras de una ideología materialista que negaba toda trascendencia. "El caso de Narodnaya Volya fue excepcional: ninguna otra organización en todo el mundo asumió de tal manera el nihilismo, aunque el anarquismo, del que también se nutrió intelectualmente compartiendo muchas ideas, se sintiera su heredero en alguna medida" (Vaquero, 2005).

Ese deseo de aniquilar el mundo presente, sin ninguna idea clara de con qué sustituirlo, este nuevo fenómeno terrorista, para André Glucksmann está infectado poderosamente de un moderno nihilismo, entendido como el deseo de destruir por destruir. ${ }^{6}$ Para Glucksmann "es fundamental reconocer que el nihilismo existe y su existencia, no está solo asociada a una religión específica, sino que está extendida por todo el planeta". "El terrorismo de nueva hornada se declara nihilista. Sin tabúes. Sin reglas. Sin fe ni ley”.

Lo sucedido el 11-S en Estados Unidos o el 11-M en Madrid anunció la llegada de un nuevo terrorismo, de una mutación del espacio de violencia, se trata del terrorismo nihilista "en el que el asesinato indiscriminado de civiles justifica el propio acto terrorista”. No hay móvil conocido ni reivindicación política, su estrategia pasa por emplear las armas contra la propia cultura que las ha originado.

Diversos analistas del fenómeno terrorista reconocen en el terrorismo yihadista un sustrato político apoyado en parámetros religiosos. Otros autores señalan que los islamistas tienen unas convicciones de

6 Para Glucksmann, a partir el tratado de Westfalia "los grandes Estados europeos combatían, principalmente, por tierras y por prestigio, pero la capacidad de construir predominaba sobre la capacidad de destruir, por lo que su supervivencia no corría peligro. Posteriormente, con el advenimiento de los totalitarismos y las guerras mundiales, la capacidad de aniquilación se desarrolló de manera espectacular, aunque esos mismos Estados totalitarios, Estados de guerra, ya sea según el modelo propuesto por Hitler o el seguido por Lenin, mantenían una importante capacidad de producción industrial, equilibrando tanto la fuerza de hacer a la fuerza de deshacer. En nuestros días, y tras los últimos acontecimientos, hemos alcanzado un tercer estadio: el nihilista, que se instala en el triunfo y la primacía de las fuerzas destructoras” Glucksmann, A. (2005a). 
carácter religioso muy marcadas y que persiguen unos objetivos políticos precisos, para lo que han elaborado unas tácticas determinada; sin embargo, para Jean Françoise Revel, la causa del terrorismo islamista, su última motivación, no es lo que la sociedad occidental hace, sino lo que es en sí; así la estrategia de buscar una solución política a este fenómeno terrorista carece de sentido, ya que no existe ningún elemento de negociación.

Si los movimientos surgidos a raíz de la Revolución Francesa, el internacionalismo socialista o el ideal anarquista nacían con vocación de extender sus ideales a toda la humanidad, el fenómeno terrorista nació y se expandió como una expresión radicalizada, en los que algunos de sus impulsos "han constituido el proceso de modernización de sus sociedades", y lo que es peor, "es uno de los contenidos de la cultura occidental que mejor ha sabido exportar a las sociedades" (Vaquero, 2005, p. 58).

Somos testigos de cómo en las sociedades occidentales, el mensaje político gira en torno al ofrecimiento a sus ciudadanos de un cambio; la clase política oferta constantemente un proyecto en torno a un cambio, como si la solución aportada hasta ese momento no tuviese solución de continuidad, o bien esta clase política percibe que la sociedad necesita constantemente devorar una y otra vez políticas y modelos sociales distintos. Este síntoma expresa una latente insatisfacción de las sociedades occidentales consigo mismas, Brazun lo describe como "una inagotable tensión emancipadora".

En las sociedades occidentales percibimos una insatisfacción latente que busca una renovación permanente, renovación que las debilita y facilita la entrada de movimientos violentos, y para salir de este laberinto del absurdo, del vacío existencialista que desarma a la sociedad, aparece el fenómeno terrorista que encontró una filosofía en que sustentarse: por medio de la violencia, por medio de la destrucción, podría salir el mundo de ese laberinto, y aquí las conductas terroristas encuentran en qué sustentar su peculiar visión del mundo.

Se ha producido un peligroso punto de inflexión al inicio del siglo XXI con respecto al fenómeno terrorista, surgiendo un terrorismo con una brutalidad extrema que ha puesto en evidencia varias cuestiones: por un lado, que las sociedades occidentales han perdido el principio 
de realidad. Si para estas sociedades todo es indiferente y relativo, ¿̇en qué fuerzas morales nos apoyaremos para afrontar el desafío del terrorismo islamista? Por otro lado, la existencia de un dato objetivo y preocupante: la incapacidad moral de buena parte de la sociedad occidental para oponer, ante el terrorismo determinados valores y principios.

André Glucksmann (2005, p. 17) afirma "La actualidad se anuncia despiadada". Las amenazas mutan peligrosamente en un horizonte difícil de prever. Si en los orígenes la capacidad de poner término a la aventura humana en este planeta era patrimonio de los dioses y posteriormente privilegio de las dos grandes potencias nucleares, ahora el poder devastador se socializa, se dispersa y cae "en la escarcela de la mayoría” esta facultad apocalíptica, se encuentra al alcance del gran público.

¿Cómo se sitúa esta constante histórica en el futuro de nuestras sociedades? Seremos testigos de nuevas amenazas, aparecerán en el horizonte de nuestras sociedades, nuevas oleadas de actividad terrorista, ya que el ambiente político y social vuelve una vez más a aparecer como impredecible y complejo, de ahí, la importancia del desarrollo de la investigación sobre los nuevos aspectos de la naturaleza de los fenómenos basados en la violencia y el terror, donde como destaca Gray Colins "casi todo se conoce, pero casi nada con el detalle necesario" (Colin, 2010)

¿Cómo puede combatir la sociedad occidental este nuevo fenómeno de violencia extrema? Actualizando su capacidad de resistencia y de sufrimiento, e involucrándose de manera activa en la resolución de las situaciones de violencia y los desafíos que nos plantea. Como afirma Bernard-Henry Levy: "no taparse la cara, romper con la política del avestruz, aceptar señalar al adversario y dotarse de los medios militares, políticos y morales para vencerlo" (Fuente Cobo, 2003), y surge la necesidad desde el ámbito del estudio científico y académico de dar una respuesta a una de las mayores amenazas a las que se enfrentan actualmente las sociedades occidentales, en esta era del terror sin fronteras, donde se ha producido una mutación del espacio de violencia donde su justificación se sustenta en el asesinato indiscriminado de civiles. 


\section{Conclusiones}

A lo largo de la historia han sucedido una serie de respuestas ante poder que han pasado en muchas ocasiones por la utilización de la fuerza, entendida esta como el uso de esta para quebrantar la voluntad del originante y para intentar una modificación o cambio del poder mismo.

Es en la sociedad, como sistema coordinado por valores, donde la autoridad política queda legitimada de acuerdo con una serie de valores sociales. En nuestros días, las herramientas que facilitan de modo pacífico y ordenado los diversos cambios políticos: elecciones periódicas, referéndums, o los mecanismos de reforma constitucional incluidos en todas las constituciones modernas, son los métodos en los cuales cada comunidad encuentra la oportunidad de revisar, incluso radicalmente, la validez y la utilidad de su sistema de gobierno, de sus instituciones y de valorar el comportamiento de su clase política, "Emitur sola virtute potestas" "El poder solo se obtiene con la virtud", destacaba Claudiano en su "De III Consulatu Honorii”, pero en el devenir de la historia, determinados movimientos ideológicos nos hablan de una tradición histórica, de conseguir un tipo de sociedad mediante el nacimiento y el desarrollo de una idea, de una doctrina. La energía de esta doctrina inspirará a determinadas corrientes políticas y a nuevos grupos a utilizar una técnica para conseguir un cambio radical y transformador de la sociedad junto a lo más importante: la esperanza, esa energía o combustible de cualquier organización terrorista, inspirada por la victoria de un grupo pequeño frente al gigante. ¿Cuándo van desaparecen las oleadas de actividad terrorista? Cuando esta energía en un momento determinado ya no pueda inspirar a nuevas organizaciones.

El patrón se repite una y otra vez a lo largo de la historia moderna, los ciclos de actividad terrorista presentan paralelismos asombrosos y una energía que les es común. Por lo tanto, podemos determinar el nacimiento, el desarrollo y el agotamiento de las oleadas de actividad terrorista.

El reflejo del empleo de la violencia y del terror sigue existiendo en nuestras sociedades, conocemos y constatamos que las oleadas de actividad terrorista aparecen y desaparecen a lo largo de la historia, el 
estudio de las pautas que han seguido en el pasado es un factor fundamental para prever una nueva oleada de actividad terrorista; por desgracia, el sentido del pasado está bastante ausente en la sociedad y en la clase política; ya Tocqueville escribía: "Toda vez que el pasado deja de arrojar su luz sobre el futuro, la mente del hombre vaga en la oscuridad". Y como nos recuerda Thérèse Delpech, apenas tenemos tiempo de observar lo que pasa o de rememorar el pasado, así, se van sucediendo los acontecimientos "como dolorosos recordatorios del malentendido que reina entre el hombre y la historia”, el reflejo continúa.

Contemplamos en el último siglo fenómenos de destrucción, de una violencia indiscriminada, y una proliferación de grupos terroristas que vemos cómo prolongan su actividad violenta durante medio siglo. Los países han evolucionado hacia un contenido normativo más justo, se han reconocido derechos antes impensables, y no solo no hemos reflejado el progreso del espíritu humano en actitudes y comportamientos menos violentos, sino que asistimos estupefactos a una representación de una nueva forma de violencia indiscriminada donde los límites de la brutalidad se han ampliado, encontrándonos frente a una violencia sin límites que llega hasta nuestras puertas a comienzos del siglo XXI.

Thérèse Delpech, destaca: "cuando intentamos eliminar el mal del corazón de la historia, lo único que logramos es convertirlo en tabú" (Delpech, 2006). Intentamos comprender, caracterizar y analizar lo sucedido en un siglo tan brutal para ponernos en guardia contra los males que aquejan el alma humana y sus terribles consecuencias, y nos auto invitamos a recuperar una reflexión histórica más amplia, en la que no debemos perder de vista la realidad social y ese conjunto de relaciones de fuerza y de relaciones de sentido que operan dentro de nuestra sociedad.

\section{Referencias}

AA.VV. (s. f.). El anarquismo europeo y sus primeras influencias en México después de la Comuna de París 1871-1881. Recuperado de http://codex. colmex.mx:8991/exlibris/aleph/a18_1/ apache_media/ 4HS1A9Y F JRCF76L 6 HRXKY 6V6P 5 9LB9.pdf. 
Avilés A., J. y Herrería A. (2008). El nacimiento del terrorismo en Occidente. Anarquí, Nibilismo y violencia Revolucionaria. Madrid: Siglo XXI.

Berkman, A. (2009). El ABC del comunismo libertario (M. Ponsa González-Vallarino, Trad.). Buenos Aires: Libros de Anarres: LaMalatesta.

Buisson, J. C. (1999). Le Siècle rebelle. Dictionnaire de la contestation an XXe siècle. París: París.

Burleigh, M. (2008). Sangre y rabia. Una historia cultural del terrorismo. Madrid: Taurus.

Delpech, T. (2006). El retorno de la barbarie en el siglo XXI.

Fojón Lagoa, J. E. (2003). Jean Françoise Revel: el realismo de la lógica. En AA.VV., Nihilismo y terrorismo (pp. 59-80). Instituto Español de Estudios Estratégicos. Ed. Ministerio de Defensa. Secretaría General Técnica. Cuadernos de estrategia. Madrid.

Franco Suanzes, J. (2003). André Gluckmann. El Nihilismo como factor Belígeno. En AA.VV., Nibilismo y terrorismo. Instituto Español de Estudios Estratégicos. Ed. Ministerio de Defensa. Secretaría General Técnica. Cuadernos de estrategia.

González Calleja, E. (1998). La razón de la fuerza. Orden Público, subversión y violencia política en la España de la Restauración (1875-1917). Madrid: Consejo Superior de Investigaciones Científicas.

Fuente Cobo, I. (2003). Bernard-Henry Levy: el filósofo del lado oscuro de la historia. En AA.VV., Nibilismo y terrorismo (pp. 117-145). Instituto Español de Estudios Estratégicos. Ed. Ministerio de Defensa. Secretaría General Técnica. Cuadernos de estrategia.

Grob-Fitzgibbon, B. (1995). Karl Heinzen y la evolución de la política del terror. Durham: Departamento de Historia, Universidad de Duke.

Glucksmann, A. (2005a). Dostoievski en Manhattan. Madrid: Taurus.

Glucksmann, A. (2005b). El discurso del odio. Madrid: Taurus.

Heller, M. (1985). El hombre nuevo soviético. De la utopía a la realidad. Barcelona: Sudamericana-Planeta.

Hoffman, B. (1999). Historia del terrorismo. Madrid: Espasa Calpe.

Kreibohm, P. (2005). La conversión al terrorismo: Una aproximación analítica. Recuperado de http://www.acague.cl/ cuadernos/cd24/tema_dos/ pdf/ Terrorismo. pdf. 
Lamarca, C. (1985) El tratamiento jurídico del terrorismo, p. 95, Centro de Publicaciones del Ministerio de Justicia, Secretaría General Técnica, Colección Temas Penales, Serie A, número 3. Madrid

Laqueur, W. (2003). Una historia del terrorismo. Barcelona: Paidós.

Lorente, J. L. (2005). Terrorismo Islámico y Occidente. VI Curso de Estado Mayor 2004-2005. CESEDEN Signatura: DE286, n. ecCatálogo 34110. Anexo 8.

Miller, M. (s. f.). The Intellectual Origins of Modern Terrorism. En M. Crenshaw (Ed.), Terrorism in Context. University Park: Pennsylvania State University Press.

MacCormick, G. H. (2003). Terrorist Decision Making. Annu. Rev. Polit. Sci. 2003. 6:473-507

Remón, J. (2006). Aproximación a la historia del terrorismo. En VV.AA., Afrontar el Terrorismo (pp. 81-95). Zaragoza: Ed. Gobierno de Aragón. Departamento de Educación Cultura y Deporte.

Vaquero Oroquieta, F. J. (2005). Terrorismo moderno y nihilismo. Revista de Pensamiento y Crítica, 93.

Veres L. (2004). Prensa, poder y terrorismo. Amnis, 4. Recuperado de http:// amnis.revues.org/706. 
LAS RAÍCES DEL TERRORISMO MODERNO Y SU CONEXIÓN CON EL MUNDO DE LAS IDEAS. LA RELACIÓN ENTRE NIHILISMO CULTURAL Y TERRORISMO POLÍTICO

\section{Anexos}

\section{Anexo 1. Manual de la Ciencia Revolucionaria de Johann Most}

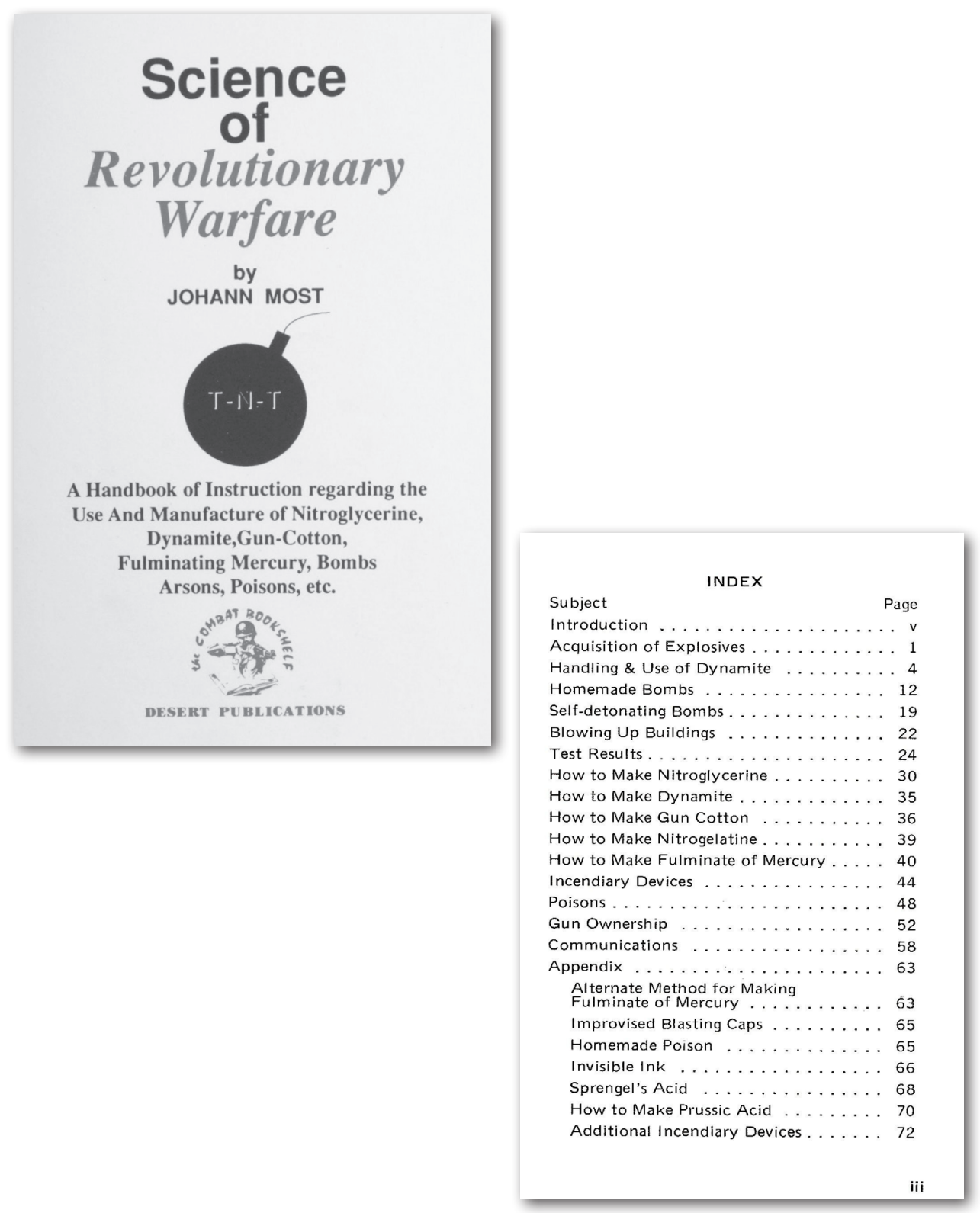


Anexo 2. Manual: "El Curso de Explosivos". Centro de prensa afiliado a Al-Qaeda. Manual en inglés para la fabricación de explosivos caseros

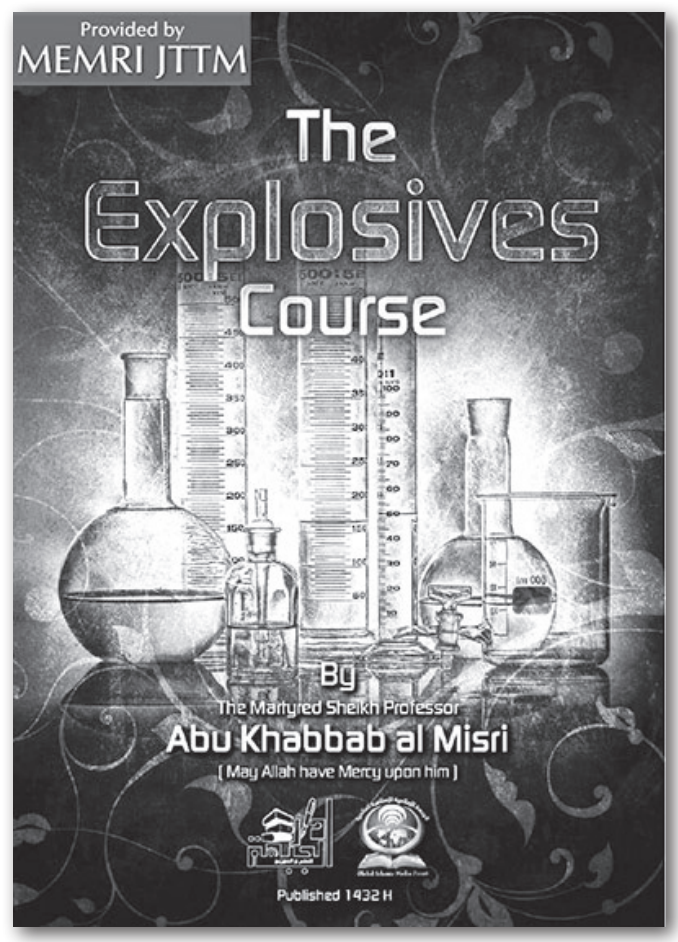

